\title{
Hamilton Depression Rating Scale 6 Clinician Version Clinical Classification
}

National Cancer Institute

\section{Source}

National Cancer Institute. Hamilton Depression Rating Scale 6 Clinician Version Clinical

Classification. NCI Thesaurus. Code C130306.

A standardized 6-item clinician rating scale for the assessment of symptoms in patients diagnosed with depression. The original 17-item Hamilton Depression Scale, developed by Max Hamilton at the University of Leeds in 1960, was independently modified by Bech, et al. in 1975, using Rasch models, to create a subscale that contains six variables. 